\title{
SEASONAL CHANGES IN FORCE PRODUCTION ACCURACY AS A MEASURE OF KINAESTHESIA IN MOTORCYCLISTS
}

original paper

( ) University School of Physical Education in Wroclaw

DOI: https://doi.org/10.5114/hm.2020.88149

\author{
STEFAN SZCZEPAN ${ }^{1}$, RYSZARD BŁACHA ${ }^{1}$, TOMASZ BROŻEK ${ }^{2}$, KRYSTYNA ZATOŃ $^{1}$ \\ ${ }^{1}$ Department of Swimming, University School of Physical Education in Wrocław, Wrocław, Poland \\ ${ }^{2}$ Graduate student, University School of Physical Education in Wrocław, Wrocław, Poland
}

\section{ABSTRACT}

Purpose. The aim of the study was to evaluate the changes in upper and lower extremity kinaesthesia during a motorcycle season in recreational riders.

Methods. The study involved 22 physically active and healthy males (age: $22.65 \pm 2.33$ years, body height: $180.35 \pm 2.89 \mathrm{~cm}$, body mass: $78.15 \pm 2.89 \mathrm{~kg}): 11$ street motorcyclists $(5.80 \pm 2.60$ years of motorcycle riding experience, $8400.00 \pm 450.00 \mathrm{~km}$ per year) and 11 individuals with no history of motorcycle riding (control group). The upper and lower extremities kinaesthesia was measured by a force-matching task replicating a handlebar and gear shift/rear brake dynamics of a motorcycle on a custom-designed kinaesthesiometer. The participants performed 10 right and left single-arm flexions and extensions and 10 right and left leg extensions at a force perceived to be equal to $98 \mathrm{~N}$. The force production accuracy (FPA) for each movement was then calculated. The testing was performed before the start of the motorcycle season (beginning of March) and 4 months into the riding season (end of June).

Results. No significant between-group or within-group differences were observed for FPA at any time point.

Conclusions. The frequent upper and lower limb movements performed by motorcyclists during 4 months of motorcycle riding may be insufficient to induce changes in FPA. Future research should include a larger sample of motorcyclists to confirm the role of kinaesthesia in this population.

Key words: motor control, kinaesthesia, muscle force control, motorcycle riding

\section{Introduction}

Motorcycle riding is one of the most popular motorized leisure activities around the world [1]. It has an inherent seasonal component in many countries at higher latitudes, limiting the riding season to approximately 6 months (e.g. in Northern European countries, i.e. Denmark, Norway, Sweden, and in the Baltic countries, i.e. Estonia, Latvia, Poland). Besides the more popular street riding of conventional and motocross motorcycles, both off-road motorcycling and amateur track racing (speedway racing) have also seen increased interest. Regardless of the riding modality, motorcycling for several minutes or hours places significant physical and physiological demands on the rider [2]. In the realm of steering-associated dynamics, the rider must constantly grip the handlebars while rotating the throttle and also performing intermittent manual actions with the clutch and brake levers. This repetitive small motor activity is coupled with the transmission of various forces through the handlebars that provide important feedback on velocity, road surface, and eventual hazards such as loss of traction [3]. Riding in challenging conditions or for long periods of time can induce several debilitating transient symptoms, including pain or paraesthesia of the upper extremities, significant lower extremity swelling, increased fatigue, decreased strength, or impaired perception [4]. These symptoms can dramatically affect the rider's safety and increase the risk of crash and injury [5]. The cognizance of these limitations has resulted in more motorcyclists seeking specific exercise interventions and motor skill assessments designed to enhance rider stamina and endurance and reduce the risk of accidents [2].

Correspondence address: Stefan Szczepan, University School of Physical Education in Wroclaw, Department of Swimming, al. I.J. Paderewskiego 35, 51-612 Wrocław, Poland, e-mail: stefan.szczepan@awf.wroc.pl

Received: October 3, 2018

Accepted for publication: June 12, 2019

Citation: Szczepan S, Błacha R, Brożek T, Zatoń K. Seasonal changes in force production accuracy as a measure of kinaesthesia in motorcyclists. Hum Mov. 2020;21(1):15-21; doi: https://doi.org/10.5114/hm.2020.88149. 
S. Szczepan, R. Błacha, T. Brożek, K. Zatoń, Changes in kinaesthesia among motorcyclists

The act of motorcycle riding requires high performance in a number of biomotor abilities, including strength, endurance, and balance/coordination. Coordination, above all, comprises the motor skill sets needed to operate a motorcycle. It includes spatial orientation or the ability to recognize the position of the body in the environment; reaction time, which is necessary to initiate and execute appropriate actions in response to a specific stimulus; and the kinaesthetic differentiation of movement or what has been termed as force perception [6], kinaesthetic feedback [7], kinaesthetic sense $[8,9]$, kinaesthetic information [10], or kinaesthetic feeling [11]. The concept of kinaesthesia was first proposed by Bastian [12] to describe the ability to sense the position and movement of the body and extremities and the awareness of the speed, direction, and amplitude of a movement. Kinaesthesia allows for the precise and efficient execution of partial movements or each of the individual phases of a complex movement [13]. Kinaesthesia is critical in all aspects of motor function, including motor control [14] and the acquisition of simple or complex motor activities [15], such as grasping objects [16], activities of daily living [17], and sports and recreational activities [11]. There exists a large kinaesthetic component in sports that require highly dynamic movements or those performed in rapidly changing environments.

In motorcycle riding, kinaesthetic differentiation allows a rider to sense movement and deliver appropriate motor responses [18]. Kinaesthetic differentiation is associated with the adjustment of muscle tension and force via the proprioceptive senses [6] and is critical in stabilizing the body, as well as allowing for more precise and efficient movement execution [19]. Enhanced kinaesthetic differentiation can improve both sensory processing and the integration of feedback from muscle tension (force component), muscle velocity (temporal component), and joint angulation (spatial component) [20]. This includes kinaesthetic feedback provided by the surrounding environment, such as the 'feeling' of water [21] or the 'feeling' of the motorcycle [22], which is understood as the perception of different external stimuli and the organization and execution of actions and movements in response to this perception. Owing to its important role in motorcycle riding, enhanced kinaesthetic awareness can allow motorcyclists to adapt more effectively to changing conditions and therefore indirectly improve safety.

As previously mentioned, motorcycle riding, particularly in difficult conditions or for long periods of time, requires highly developed motor skills in both the fitness (strength and endurance) and coordination/bal- ance (spatial orientation, reaction time, kinaesthesia) domains. Despite the fact that motorcycling is an immensely popular leisure activity, no research to date has investigated the kinaesthetic differentiation in motorcyclists. An analysis of the changes that occur during the riding season can improve our understanding of kinaesthesia in this population and also aid in the development of riding programs to counteract performance degradation during the off season. The evaluation and, later, training of kinaesthetic perception may enhance motorcycle safety by expanding knowledge on this critical aspect of motorcycling. Therefore, the aim of the present study was to evaluate the changes in upper and lower extremity kinaesthetic differentiation during the motorcycle season among recreational riders. We assumed that kinaesthetic differentiation would improve as the motorcycle season progressed.

\section{Material and methods}

\section{Subjects}

Overall, 22 physically active and healthy males (age: $22.65 \pm 2.33$ years, body height: $180.35 \pm 2.89 \mathrm{~cm}$, body mass: $78.15 \pm 2.89 \mathrm{~kg}$ ) were recruited. All were right-handed. There were 11 recreational street motorcyclists $(5.80 \pm 2.60$ years of riding experience) and 11 individuals with no history of motorcycle riding, who served as a control group. The motorcyclists rode $8400.00 \pm 450.00 \mathrm{~km}$ per year with an average weekly riding time of approximately 8 hours $(550 \mathrm{~km})$. The riding terrain was largely urban and suburban roads. The motorcycles used by the participants were either of the sport, super sport, sport touring, or super moto variety, manufactured in years 1995-2010 and weighing 150-250 kg. Engine displacement was $500-1100 \mathrm{~cm}^{3}$, with power production of $36-127 \mathrm{~kW}$. All motorcycles had 4-cylinder engines with mechanically controlled throttles and transmissions and a mechanical or hydraulic clutch. They were equipped with an adjustable or non-adjustable inverted front fork, swingarm rear suspension with either single or twin shock absorbers, and handlebars mounted either on the top of the yoke or on the fork tubes as clip-ons. Some had steering dampers and anti-lock braking systems. None of the motorcycles was equipped with any modern advancements such as stability or balance control systems. All were street legal and roadworthy. During the study, both groups maintained their normal lifestyle, including diet and sleeping habits, and did not participate in any external training or inter- 
vention that could enhance kinaesthetic differentiation. The participants were instructed to refrain from alcohol and caffeine 24 hours before testing [23].

\section{Testing apparatus}

Upper and lower extremity kinaesthetic differentiation was quantified by a force sense assessment in which the accuracy of reproducing a pre-specified force was measured [6, 14, 17, 19]. For the purposes of the study, a custom-designed kinaesthesiometer (Polish patent \#PL213505B1) was selected as the device can measure the force applied by the upper and lower extremities in a variety of movements [24]. The device had previously been tested and verified as a valid diagnostic tool in sense of force assessments [14, 24, 25]. It uses an adjustable exercise chair modified to include 2 pedals and 2 hand levers connected to straingauge force sensors (Figure 1). The sensors and the integrated signal conditioning and data acquisition instrumentation processed the sensor data and outputted force measures on a computer where they were registered. The kinaesthesiometer was adapted to mimic the riding position on a motorcycle with the pedals and hand levers arranged so as to replicate the gear shift/brake and throttle/clutch movements by

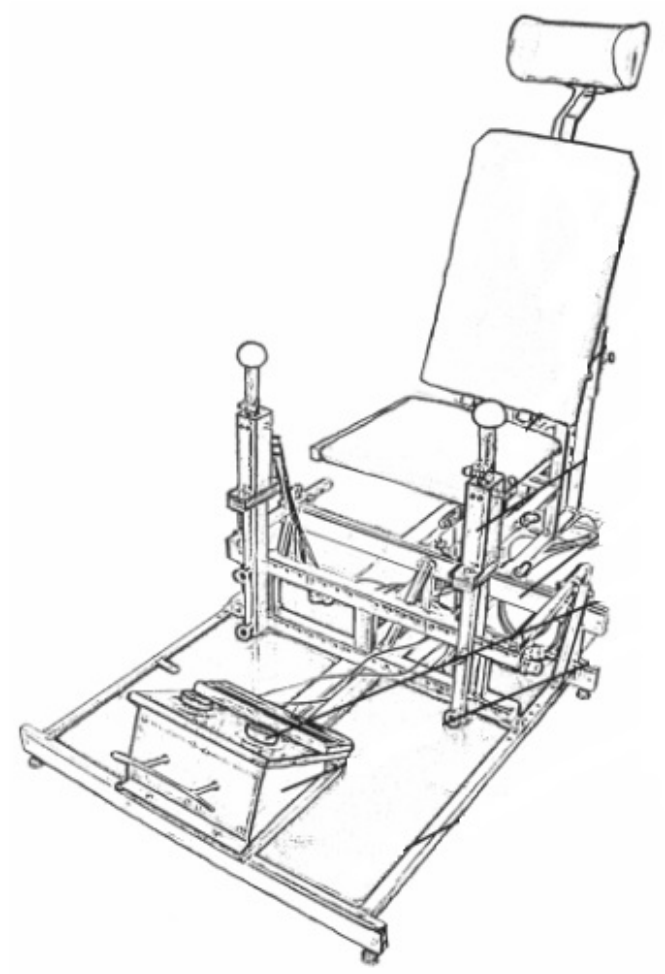

Figure 1. The kinaesthesiometer for measuring repeated upper and lower extremity isometric force (reprinted from [26]) the legs and hands, respectively. Before each trial, the seat height was adjusted for the participant and the device was calibrated with 1-, 5-, and 10-kg weights.

\section{Procedure}

The testing was performed twice, with a pre-test administered at the beginning of March, before the start of the motorcycle season, and a post-test administered at the end of June, or 4 months into the riding season. The participants attended a familiarization trial, in which a monitor provided an instantaneous reading of the applied force. This visual feedback allowed the subjects to anticipate the force required in the test proper. A maximum force trial was performed, and the group mean was recorded. All testing was carried out in the seated position without back support to negate the effects of back exteroreceptors and to mimic motorcycle riding posture. No visual feedback on force output was provided during the experimental phase of the test. The participants were to reproduce a force they believed to be equal to $50 \%$ of the maximum force group mean $(98 \mathrm{~N})$. This level of force had also been previously used in isometric muscle testing [14, 27].

During the upper extremity testing, one hand remained on the lever while the other one rested freely on the thigh. The task was to perform 10 single-arm flexions and extensions at the elbow at a force that was perceived to be equivalent to $98 \mathrm{~N}$. The goal was to reproduce this force in each repetition. The flexion/ extension repetitions were separated by 4 -s intervals. Testing was first performed with the right hand and then with the left hand. The participant had to use their hand to pull the lever towards the body (along the sagittal plane) during the flexion phase of the movement and push the lever away from the body during the extension phase.

Lower extremity testing took place with both feet resting on the pedals of the kinaesthesiometer, which were placed at a slight incline from the base of the device, and arms crossed over the chest in order to eliminate proprioceptor feedback. The goal of the task was to perform 10 single-leg extensions at the knee and apply a force perceived to be $98 \mathrm{~N}$ on the pedal. During this test, the participant pressed the pedal in the sagittal plane away from the body. As in the upper extremity test, the repetitions were separated by 4-s intervals; the testing was first performed with the right and then with the left leg.

The level of kinaesthetic differentiation was determined for each task by first averaging the force 
S. Szczepan, R. Błacha, T. Brożek, K. Zatoń, Changes in kinaesthesia among motorcyclists

values across the 10 repetitions. The absolute difference between this mean and each individual repetition was then determined and again averaged. This mean of the sum of differences of the force generated across the 10 repetitions provided a measure of force production accuracy (FPA). This variable had been previously determined as a valid measure of kinaesthetic differentiation [26, 28], in which the lower the magnitude, the less variability in force between each repetition and therefore enhanced level of kinaesthetic sense [14].

\section{Data analysis}

The distribution of the data set was screened for normality with the Shapiro-Wilk test. Levene's test for equality of variances was also performed. Analysis of variance (ANOVA) for repeated measures with Tukey's post-hoc test was used to compare group means at each time point (pre-test and post-test). Student's $t$ test served to compare age and body height and mass [29]. The alpha level of 0.05 was assumed as statistically significant; data are reported as means \pm standard deviations.

\section{Ethical approval}

The research related to human use has complied with all the relevant national regulations and institutional policies, has followed the tenets of the Declaration of Helsinki, and has been approved by the Ethics Committee for Research at the University School of Physical Education in Wrocław, Poland.

\section{Informed consent}

Informed consent has been obtained from all individuals included in this study.

\section{Results}

No statistically significant between-group differences were observed for age, body height, or body mass $(p>0.05)$. Between-group comparisons of pre- and posttest FPA revealed no differences between the motorcyclists and the control group. Within-group comparisons also showed no changes in FPA for all movements. Table 1 displays the pre- and post-test FPA data for both groups.

\section{Discussion}

Considering the relative importance of kinaesthetic differentiation in motorcycle riding, no studies have yet investigated this aspect of the motor control system, hence the underlying basis of the present study. Despite the frequent elbow extensions that occur in response to vertical handlebar motion and the manipulation of hand controls, we did not confirm our hypothesis that kinaesthetic differentiation improved as the motorcycle season progressed. We had expected that the repetitive hand movement required to modulate motorcycle speed, in which the right hand modulates the throttle/front brake and the left hand controls the clutch [22], would enhance FPA. Similarly, for lower extremity force repeatability, we expected that the use of the right leg for braking and the left leg for gear changes would also lead to an improvement in lower extremity FPA. Our results suggest that the repetitive upper and lower extremity movements performed by this group of recreational motorcyclists may be insufficient to induce changes in FPA.

A number of studies have used force repeatability as a measure of kinaesthetic differentiation [6, 17, 19]. The kinaesthesiometer and methodology applied in the present study had been previously validated by

Table 1. Upper and lower extremity FPA including between- and within-group comparisons [N]

\begin{tabular}{|c|c|c|c|c|c|c|c|c|c|c|c|c|}
\hline \multirow{4}{*}{ Movement task } & \multicolumn{12}{|c|}{$\operatorname{FPA}(\mathrm{N})$} \\
\hline & \multirow{2}{*}{\multicolumn{2}{|c|}{$\begin{array}{c}\text { Pre-test (March) } \\
\text { Group }\end{array}$}} & \multicolumn{2}{|c|}{ Between-group } & \multirow{2}{*}{\multicolumn{2}{|c|}{$\frac{\text { Post-test (June) }}{\text { Group }}$}} & \multicolumn{2}{|c|}{ Between-group } & \multicolumn{4}{|c|}{ Within-group } \\
\hline & & & \multirow{2}{*}{$-c_{(\mathrm{C}-\mathrm{M})}$} & \multirow{2}{*}{$\begin{array}{c}p \\
(\mathrm{C}-\mathrm{M})\end{array}$} & & & \multirow{2}{*}{$\begin{array}{c}\Delta \\
(\mathrm{C}-\mathrm{M})\end{array}$} & \multirow{2}{*}{$\begin{array}{c}p \\
(\mathrm{C}-\mathrm{M})\end{array}$} & \multirow{2}{*}{$\begin{array}{c}\Delta \\
(\mathrm{C}-\mathrm{C})\end{array}$} & \multirow{2}{*}{$\begin{array}{c}p \\
(\mathrm{C}-\mathrm{C})\end{array}$} & \multirow{2}{*}{$\begin{array}{c}\Delta \\
(\mathrm{M}-\mathrm{M})\end{array}$} & \multirow{2}{*}{$\begin{array}{c}p \\
(\mathrm{M}-\mathrm{M})\end{array}$} \\
\hline & $\mathrm{C}$ & M & & & $\mathrm{C}$ & M & & & & & & \\
\hline Right elbow, extension & $11.16 \pm 4.36$ & $12.04 \pm 5.51$ & 0.88 & 0.997 & $8.82 \pm 3.20$ & $9.15 \pm 3.45$ & 0.33 & 0.999 & -2.34 & 0.461 & -2.89 & 0.149 \\
\hline Right elbow, flexion & $8.46 \pm 2.78$ & $10.34 \pm 3.62$ & 1.88 & 0.841 & $7.31 \pm 3.11$ & $8.76 \pm 3.04$ & 1.45 & 0.885 & -1.15 & 0.975 & -1.58 & 0.839 \\
\hline Left elbow, extension & $8.99 \pm 3.48$ & $11.19 \pm 3.39$ & 2.20 & 0.707 & $7.43 \pm 2.29$ & $9.04 \pm 3.19$ & 1.61 & 0.812 & -1.56 & 0.876 & -2.15 & 0.515 \\
\hline Left elbow, flexion & $9.76 \pm 4.21$ & $9.91 \pm 3.46$ & 0.15 & 1.000 & $7.91 \pm 3.69$ & $8.42 \pm 3.65$ & 0.51 & 0.919 & -1.85 & 0.743 & -1.49 & 0.880 \\
\hline Right knee, extension & $10.60 \pm 3.03$ & $13.75 \pm 5.10$ & 3.15 & 0.297 & $9.35 \pm 3.34$ & $10.89 \pm 3.83$ & 1.54 & 0.882 & -1.25 & 0.866 & -2.86 & 0.439 \\
\hline Left knee, extension & $14.49 \pm 3.98$ & $16.19 \pm 7.50$ & 1.70 & 0.776 & $15.05 \pm 7.69$ & $16.21 \pm 8.39$ & 1.16 & 0.945 & 0.56 & 0.985 & 0.02 & 1.000 \\
\hline
\end{tabular}

FPA - force production accuracy, C - control group, $\mathrm{M}$ - motorcyclist group

Negative $\Delta$ indicates an improvement in FPA. 
Zatoń and Błacha [24] and Błacha [14]. Other studies on kinaesthetic differentiation measured handgrip strength with a hand dynamometer [17] or isometric contraction force of the upper extremities [30]. Zaton et al. [26] evaluated the effects of exercise and fatigue on the repeatability of force production, observing a positive effect on sub-maximal force accuracy. Earlier, Zaton et al. [28] examined the relationship between skiing and kinaesthetic differentiation to find that individuals with extended skiing experience presented significantly better kinaesthetic sense than non-skiers. Colwin [21], in turn, reported that swimmers with a higher level of kinaesthetic differentiation showed enhanced swim stroke mechanics as compared with swimmers with a poorer level of kinaesthetic differentiation. Furthermore, swimmers with high kinaesthetic differentiation often exhibited more precise inwater swim technique. A more recent work by Pinzon et al. [7] showed a positive effect of kinaesthetic training on muscle memory and on motor skill learning. They found that the knowledge gained from kinaesthetic-only feedback significantly improved muscle memory and task execution. The lack of changes in kinaesthesia among our group of motorcyclists suggests that not all physical activities and associated interventions can improve kinaesthetic differentiation.

From a practical standpoint, the present study provides insight on changes in kinaesthetic differentiation during such a seasonal recreational activity as motorcycle riding and can serve as a baseline for future research in this domain. Kinaesthetic differentiation, particularly of the hands, is an important sense in fine motor skill execution [31], and deteriorated hand position sense can negatively affect hand function [16]. Among motorcyclists, a high level of kinaesthetic differentiation could allow for enhanced control of the motorcycle and benefit the rider when encountering dangerous situations on the road. On the other hand, individuals with weaker motor skills or less prepared for the motorcycle season could take advantage of modern technological aids, including devices that support various riding tasks (braking and acceleration) as well as balance. Among the latter, the newly introduced Riding Assist technology (Honda, Japan) analyses the position of the motorcycle and automatically controls the steering wheel to maintain balance. The same balance system used in this motorcycle had been previously applied in the ASIMO humanoid robot (Honda, Japan), allowing it to walk, run, avoid obstacles, and interact with the environment [32].

It should be noted that the results of this study need to be interpreted with caution because of several limi- tations. Our findings are limited to young, healthy males involved in recreational street motorcycling. The selection of a 4-s interval between the repetitions was not validated nor was it confirmed to be of sufficient duration to eliminate the effects of fatigue. Additionally, testing was based on reproducing a force of $98 \mathrm{~N}$ and not a percentage of individual maximal force. In retrospect, it would have been more prudent to perform a series of isometric contractions at $25 \%$ or $50 \%$ of individual maximal force. Furthermore, previous training history or involvement in safety courses was not analysed and may have influenced the level of kinaesthetic differentiation. Finally, while none of the participants rode on newer motorcycles equipped with balance or stability aids, the types of motorcycles they rode on may have influenced the results. Finally, the post-test should have been administered at the end of the motorcycle season although we had surmised that 4 months of motorcycle riding should have been sufficient to induce changes in FPA. Future research should address these limitations.

Other intrinsic factors that may be associated with changes in kinaesthetic differentiation include improved musculotendinous control and greater force production, the latter being dependent on the biomechanical modulation of muscle tension [33]. Additional research is needed to measure changes in muscle tension during the motorcycle season as this variable was not considered in the present study.

\section{Conclusions}

No significant between-group or within-group differences were observed for FPA across all the movements. This suggests that the frequent upper and lower limbs actions performed during motorcycle riding may be insufficient to induce changes in FPA. Future research should confirm these results by including larger samples of motorcyclists (grouped by motorcycle type and riding experience) and by assessing FPA at the end of the motorcycle season. A greater understanding of FPA changes and associated causes could enhance our knowledge of kinaesthesia in motorcyclists and improve riding skill and safety.

\section{Disclosure statement}

No author has any financial interest or received any financial benefit from this research.

\section{Conflict of interest}

The authors state no conflict of interest. 
S. Szczepan, R. Błacha, T. Brożek, K. Zatoń, Changes in kinaesthesia among motorcyclists

\section{References}

1. Singh R, Theobald P, Hamad AK, Hay S. Motocross biking for competition and for recreation: a prospective analysis of 423 injured riders. BMJ Open Sport Exerc Med. 2015;1(1):e000019; doi: 10.1136/bmjsem-2015000019.

2. Simões VR, Crisp AH, Verlengia R, Pellegrinotti IL. Neuromuscular and blood lactate response after a motocross training session in amateur riders. Asian J Sports Med. 2016;7(2):e23805; doi: 10.5812/asjsm.23805.

3. Jans C, Peersman G, Peersman B, Van Den Langenbergh T, Valk J, Richart T. Endoscopic decompression for chronic compartment syndrome of the forearm in motocross racers. Knee Surg Sports Traumatol Arthrosc. 2015;23(9):2522-2527; doi: 10.1007/s00167-014-3044-z.

4. Grange JT, Bodnar JA, Corbett SW. Motocross medicine. Curr Sports Med Rep. 2009;8(3):125-130; doi: 10.1249/ JSR.0b013e3181a61e95.

5. Shaker RH, Eldesouky RSh, Hasan OM, Bayomy H. Motorcycle crashes: attitudes of the motorcyclists regarding riders' experience and safety measures. J Community Health. 2014;39(6):1222-1230; doi: 10.1007/s10900014-9883-1.

6. Raczek J, Mynarski W, Ljach W. Developing and diagnosing coordination motor skills: a manual for teachers, trainers and students [in Polish]. Katowice: AWF; 2003.

7. Pinzon D, Vega R, Sanchez YP, Zheng B. Skill learning from kinesthetic feedback. Am J Surg. 2017;214(4): 721-725; doi: 10.1016/j.amjsurg.2016.10.018.

8. Wolny T, Saulicz E, Linek P, Myśliwiec A. Two-point discrimination and kinesthetic sense disorders in productive age individuals with carpal tunnel syndrome. J Occup Health. 2016;58(3):289-296; doi: 10.1539/ joh.15-0108-OA.

9. Buśko K, Górski M, Nikolaidis PT, Mazur-Różycka J, Łach P, Staniak Z, et al. Leg strength and power in Polish striker soccer players. Acta Bioeng Biomech. 2018;20(2): 109-116; doi: 10.5277/ABB-01066-2017-02.

10. Schmidt RA, Lee TD. Motor learning and performance. From principles to application, $5^{\text {th }}$ ed. Champaign: Human Kinetics; 2013.

11. Klarowicz A, Zatoń K. Changes in kinesthetic differentiation during program of fitness swimming for students. Ann Univ M Curie-Skłodowska Sect D Med. 2006; 60(Suppl. 16),3(291):258-261.

12. Bastian HC. The "muscular sense"; its nature and cortical localisation. Brain. 1887;10(1):1-89; doi: 10.1093/ brain/10.1.1.

13. Meinel K, Schnabel G. Kinematics - motor skills: schema of theory of motor skills in the pedagogical aspect [in German]. Berlin: Sportverlag; 1998.

14. Błacha R. Repeatability of isometric muscle tension as a measure of kinesthetic differentiation ability [in Polish]. Wrocław: AWF; 2013.

15. Harris SJ, Livesey DJ. Improving handwriting through kinesthetic sensitivity practice. Aust Occup Ther J. 1992; 39(1):23-27; doi: 10.1111/j.1440-1630.1992.tb01731.x.
16. Matheson LN, Kaskutas VK, Mada D. Development and construct validation of the hand function sort. J Occup Rehabil. 2001;11(2):75-86; doi: 10.1023/A:10166512 01397.

17. Mustafa K, Furmanek MP, Knapik A, Bacik B, Juras G. The impact of the Swedish massage on the kinesthetic differentiation in healthy individuals. Int J Ther Massage Bodywork. 2015;8(1):2-11; doi: 10.3822/ijtmb. v8i1.252.

18. Lovelace EA, Aikens JE. Vision, kinesthesis, and control of hand movement by young and old adults. Percept Mot Skills. 1990;70(3 Pt 2):1131-1137; doi: 10.2466/pms. 1990.70.3c.1131.

19. Docherty CL, Arnold BL. Force sense deficits in functionally unstable ankles. J Orthop Res. 2008;26(11): 1489-1493; doi: 10.1002/jor.20682.

20. Klarowicz A, Zatoń K, Albiński P. Differences in conscious reception of stimuli from water environment in school children participating in rehabilitation swimming program. Pol J Environ Stud. 2006;15(5B Pt 2): 643-645.

21. Colwin CM. Breakthrough swimming. Champaign: Human Kinetics; 2002.

22. Parks L. Total control: high performance street riding techniques, $2^{\text {nd }}$ ed. Minneapolis: Motorbooks; 2015.

23. Atkinson G, Reilly T. Circadian variation in sports performance. Sports Med. 1996;21(4):292-312; doi: 10.2165/ 00007256-199621040-00005.

24. Zatoń M, Błacha R. The manner of measurement of force of pressure of human limbs and device for measurement of force of pressure of human limbs [in Polish]. Bulletin of the Patent Office. 04.08.2008. Availablefrom:https://pl.espacenet.com/publicationDetails/ biblio?FT $=$ D\&date $=20080804 \& \mathrm{DB}=\&$ locale $=$ pl_PL\& $\mathrm{CC}=\mathrm{PL} \& \mathrm{NR}=381581 \mathrm{~A} 1 \& \mathrm{KC}=\mathrm{A} 1 \& \mathrm{ND}=4$.

25. Blacha R, Zaton K, Piwowarczyk P, Jastrzebska A, Szczepan S. Repeatability of force production as a measure of kinaesthetic sense in seagoing sailors and recreational sailors. Hum Mov. 2019;20(2):57-63; doi: 10.5114/hm.2019.83219.

26. Zatoń M, Błacha R, Jastrzębska A, Słonina K. Repeatability of pressure force during elbow flexion and extension before and after exercise. Hum Mov. 2009;10(2): 137-143; doi: 10.2478/v10038-009-0010-6.

27. Hebisz R, Blacha R, Hebisz P, Szczepan S. The relationship between the gross efficiency and the ability to repeat the given pressure force in trained cyclists. Hum Mov. 2019;20(1):48-54; doi: 10.5114/hm.2019.79217.

28. Zatoń M, Zatoń K, Zygadło A. Changes in kinesthetic differentiation capacity in the ski learning process [in Polish]. Antropomotoryka. 2008;18(44):37-47.

29. Thomas JR, Nelson JK, Silverman SJ. Research methods in physical activity, $7^{\text {th }}$ ed. Champaign: Human Kinetics; 2015.

30. Jones LA, Hunter IW. Force sensation in isometric contractions: a relative force effect. Brain Res. 1982;244(1): 186-189; doi: 10.1016/0006-8993(82)90919-2. 
31. Lynch MR, Raymer ME, Elvery JH, Walsh AL, Burns YR. The development of hand position sense. New Zealand J Physiotherapy. 1992;20:15-20.

32. Jaeger CB, Levin DT. If Asimo thinks, does Roomba feel? The legal implications of attributing agency to technology. J Hum Robot Interact. 2016;5(3):3-25; doi: 10.5898/JHRI.5.3.Jaeger.

33. Proske U, Gandevia SC. The kinaesthetic senses. J Physiol. 2009;587(Pt 17):4139-4146; doi: 10.1113/ jphysiol.2009.175372. 